\title{
Green Practices for Sustainable Development: A Study on Readymade Garment (RMG) Industries of Bangladesh
}

Bijeta Saha

Department of Management Information Systems

University of Dhaka, Dhaka-1000, Bangladesh

Md. RakibulHoque

Center for Modern Information Management, School of Management

Huazhong University of Science and Technology

Wuhan, China

\begin{abstract}
Readymade garment (RMG) industries are one of the major foreign currency earners of Bangladesh. Large number of RMGs can play vital role to cope climate change challenges. The present study is an attempt to address the existing green practices of readymade garments industries to ensure environmental sustainability. Both qualitative and quantitative analyses were carried out in 34 RMGs. A semi structured questionnaire was used to interview social compliance manager of randomly selected RMGs. About 29\% of RMGs had already implemented green practices in ICT area to preserve environment and ecological innovation. These RMGs also minimized the paper consumption significantly as a commitment towards environmental stewardship. Additionally, it was noted from present research that 59\% of RMGs switched off personal computer after use to minimize the energy consumption. Nearly $88 \%$ respondents responded that individual consideration prompt the application of Green IS. The study also highlighted the overall green practices of garment industries.
\end{abstract}

Keywords: Green ICT, Sustainability

Received: 10 January 2018, Revised 9 February 2018, Accepted 18 February 2018

DOI: $10.6025 / \mathrm{jio} / 2018 / 8 / 2 / 70-75$

(C) 2018 DLINE. All Rights Reserved

\section{Introduction}

Environmental sustainability means reduction of nonrenewal natural resources consumption and improves the efficiency of existing technology. All over the world, various organizations have implemented different techniques to minimize the conventional resource consumption and introduced diverse technology. Since 1990s, readymade garment industry becomes pivotal foreign currency earners of Bangladesh. This industry is mushrooming in rapid pace and turns into largest job provider of this country.

\begin{tabular}{lllllll}
\hline 70 & Journal of Information Organization Volume & 8 & Number 2 & June & 2018
\end{tabular}


Climate change is the global phenomenon that drags the concentration of policy makers and forces to adopt less carbon producing techniques or technology. Considering this, garment industries are discovering the possible way to minimize their carbon footprint. There is an intricate relationship between climate changes and green IT practices (Elliot, 2011). However, this green practice can indirectly reduce the energy consumption and most of the energy produces from traditional natural resources like as coal, oil and gas (Molla et al., 2009). These resources consider as the main malefactor of greenhouse gas production. Therefore, any initiative to reduce energy consumption is also counted as combating climate change.

Garment industry requires less amount of energy to sewing fabric. Thus, this industry is not considered as significant amount of carbon emission in comparison with other manufacturers. However, these industries have already adopted different mechanism to minimize the energy consumption. Nevertheless, limited relevant research has carried out so far to address their practices. Thus, this paper is an attempt to identify the existing green practices of garment industries to ensure sustainable development.

\section{Literature Review}

Green objectives may be achieved through Green Design, Green Manufacturing, Green use and Green disposal. Manufacturing operations creates environmental issues such as - water, electricity, chemicals that directly or indirectly generates carbon dioxide, hazardous wastes hinders the way to go Green. In daily operations organizations use computers, servers or other peripherals devices that results in greenhouse gas emissions as well. Here Green IT initiates allows an organization to attract more customers to buy their products that will add value towards the organization. Today Organizations promotes Green IT strategy for environmental sustainability, economic growth enhancing the value of social equity (Chou \& Chou, 2012). Molla et.al (2011) identified G-readiness framework that contains five components - Green IT attitude, Green IT policy, Green IT practices, Green IT Technology and Green IT governance.

Green practices in Malaysia has been initiated almost fifty years ago with 'No smoking' and 'Energy savings' campaigns including animal and land conservation, recycling etc. Furthermore initiatives are also to support Green environment which includes 'Green infrastructure', 'Green Hub', efficient use of resources but real progress is still far behind (Din et.al, 2013).

Indian leading Manufacturing Company Honda has taken Green initiatives by adopting fuel efficient cars that results in an increase of sales figures by $28 \%$ compared to the last four years. Similarly in GE where initiatives taken on Clean Technology to reduce greenhouse effects in their jet engines, wind turbines has risen their revenue by 6 billion (Robinson, 2015).

Today Green Industry Leaders take decisions beneficiary but not negligible to the environment. They believe in practicing less usage of harmful chemicals \& wastages, lower carbon footprints promoting energy efficiency, cost savings and more green business opportunities in the years ahead (Green Industry Analysis, 2015). Singapore's first Green factory 'Greenhub' constitutes eco-friendly processes from construction to operations. It has self-tinting windows to control excess heat, quantified carbon footprint during construction phase, re-design packaging solutions, less fuel consumption during export, disposal of wastes methods that proves their environmental protection strategy as a commercially successful initiative (Channel News Asia, 2013).

Currently in Europe three sharp factories out of four has been qualified as super Green Factories. Sorting waste materials plastic, paper, glass, batteries are one of their core eco strengths. It reduces their transportation \& packaging requirements make the efficient use of resources with the recycling of old products. From 2006-2007 it reduced 24\% of its landfill waste, $23 \%$ energy usage, $48 \%$ water consumption and awarded Wales Business and sustainability award for eco-friendly and sustainable future (Sharp, 2015).

\section{Green Practices}

A contribution big or small towards ecological balance in planet to preserve natural resources through daily practices for the long term sustainability on the earth is considered as Green Practices. It involves - reduced consumption of, energy, pollution (air, water and soil), wastes, conservation of scare resources etc. The purpose of Green practices in the organizations is to ensure living life of humans and creatures on earth are yet sustainable.

There need to consider some elements to evaluate whether the factory is practicing Green policies or not in their activities. These includes - 
- Sustainable design \& construction of buildings - Manufacturing plants, offices premises, warehouses and so on.

- Consideration of Smart Energy Management Systems - Pc/ laptops with energy savings features, use of LED bulbs, adaptation of E-modules, discard of electronic items, tendency of keeping pc/computers/peripherals on switching off/ sleep mode and so on.

- Consideration of Smart route plan to avoid or reduce the necessity of individual travel, trucks or other vehicles travel that eventually reduce consumption of fuel, carbon emissions, fuel.

- Adaptation of waste recycling.

- Management of Pollution, lean Management.

- Reduced need of paperwork, print Inks etc.

\section{Methodology}

The study was both qualitative and quantitative in nature. A semi structured questionnaire had been followed in identifying why, how and in what level RMGs in Bangladesh's were considering Green practices in their working premises. About 34 social compliance managers of different RMGs were interviewed to identify their existing green practices. Additionally, relevant critical assessments of some of the articles, journals, documents were also made to prepare literature review section.

\section{Findings \& Analysis}

The present study is an attempt to find how and in what extents organizations practice Green ICT in their environment. The research considers five questions and the analysis of the findings from the study are thoroughly described. Studying on 34 Readymade Garment Organizations, it is found that $24 \%$ of the organizations consider Green practices because they just have to improve their corporate image. They are taking green initiatives in their marketing campaigns showing their interests in preserving the environment ensuring longevity in the marketplace. Nearly $18 \%$ of the organizations are found in recognizing the actual importance of Green practices being socially sensible while $29 \%$ of the organizations seem more cautious in preserving environment like- putting restrictions on those activities that cause environmental degradation. Remaining $29 \%$ of the organizations believe in the development of socially acceptable products and processes resulting in sustainability.

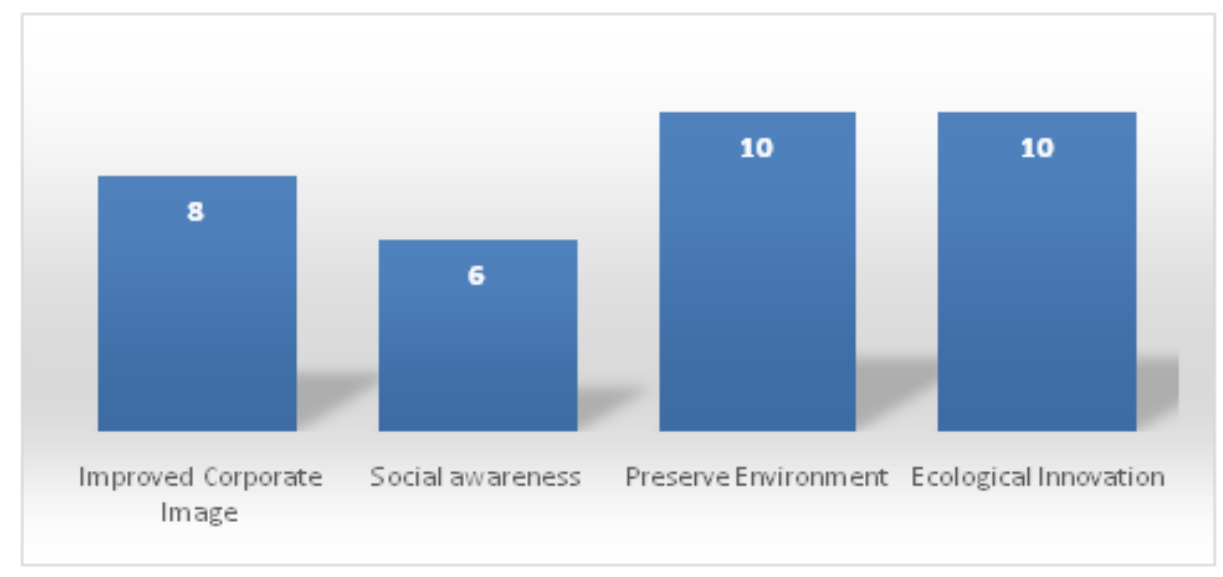

Figure 1. Various points which inspire to introduce Green Practices

Organizations are asked to mention the reasons behind the adoption of Green practices in their environment where only $15 \%$ are answered 'Reduced energy consumption' through using Solar, LED bulbs, 24\% practices less paper consumption in their premises. They believe that valuing paper as a resource rather than a disposable commodity may cut climate change emissions, saves money (Costs of Photocopy, printer inks) and curb deforestation.

Only $6 \%$ of the firms practice proper disposal and management of waste. They believe in increasing the recycling rate of waste 


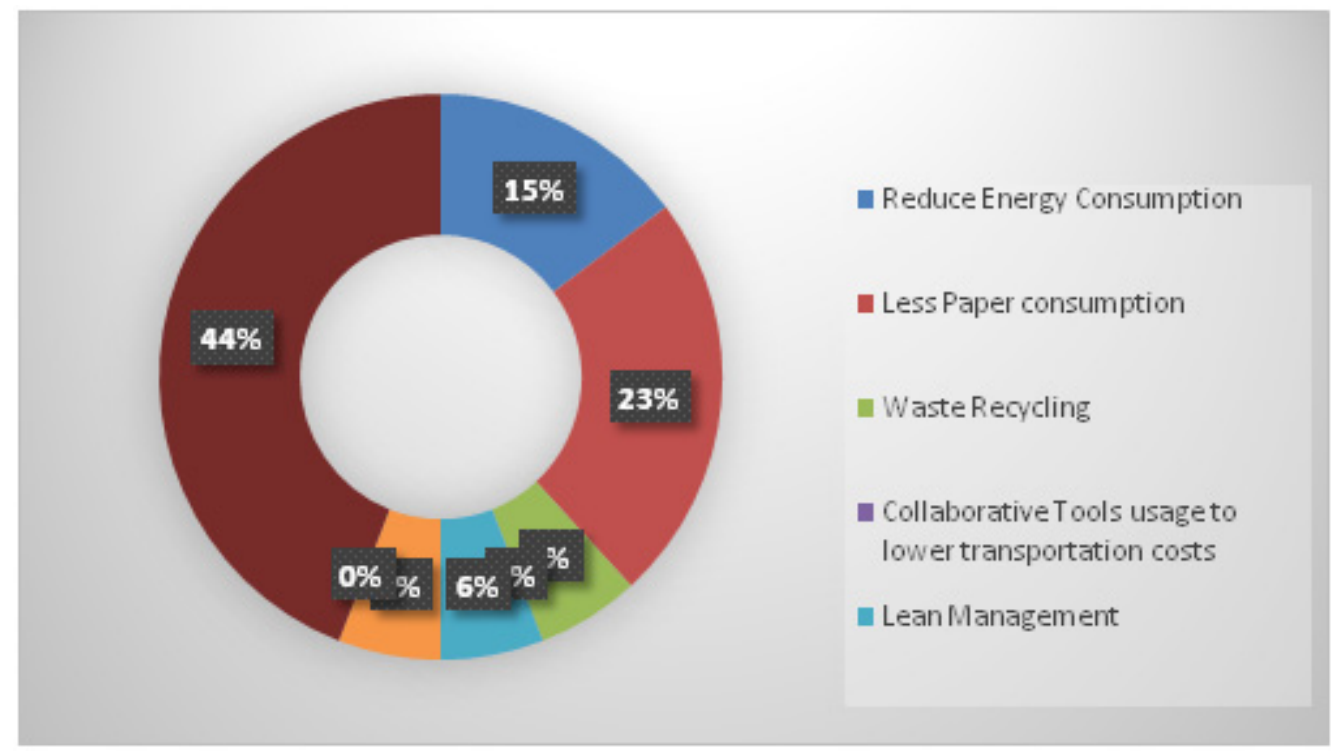

Figure 2. Organizations Performs Green Practices

materials moving ahead in achieving zero waste emissions. No organizations are found in practicing collaborative tools for lowering transportation costs and product stewardship. Collaborative tools may include sharing of trucks, vehicles reducing frequency of trips, empty running and so on. On the other hand, Product stewardship is a strategy where a person directly or indirect linked to the products life cycle are held responsible for minimizing its impact on environment. $6 \%$ of the organizations practices lean management while another $6 \%$ are found cautious in pollution management. They believe that pollution on only harms environment but also costs businesses. Hazardous wastes including liquids, solids, sludge should not be disposed in the lands or water since it is harmful to the health of workers, local residents, animals and plants. $44 \%$ of the organizations that have mentioned some other reasons, added this less consumption of hazardous chemicals in their factories as one of their concerns. Some are found in promoting renewable energy for sustainable development in long run too.

Organizations are also asked to mention the number of items that they use for promoting Green ICT. About 59\% respondents say that they switch off computers/printers and other peripherals after use which is undoubtedly a very positive sign in energy savings. Other $41 \%$ considers PC/laptop with energy saving features which means more energy efficient computers that lower electricity costs for the businesses and reduces carbon emissions to protect environment. They use power surge protectors. Discard of the electronic items and usages of electronic modules for distant learning have not yet practiced by the organizations.

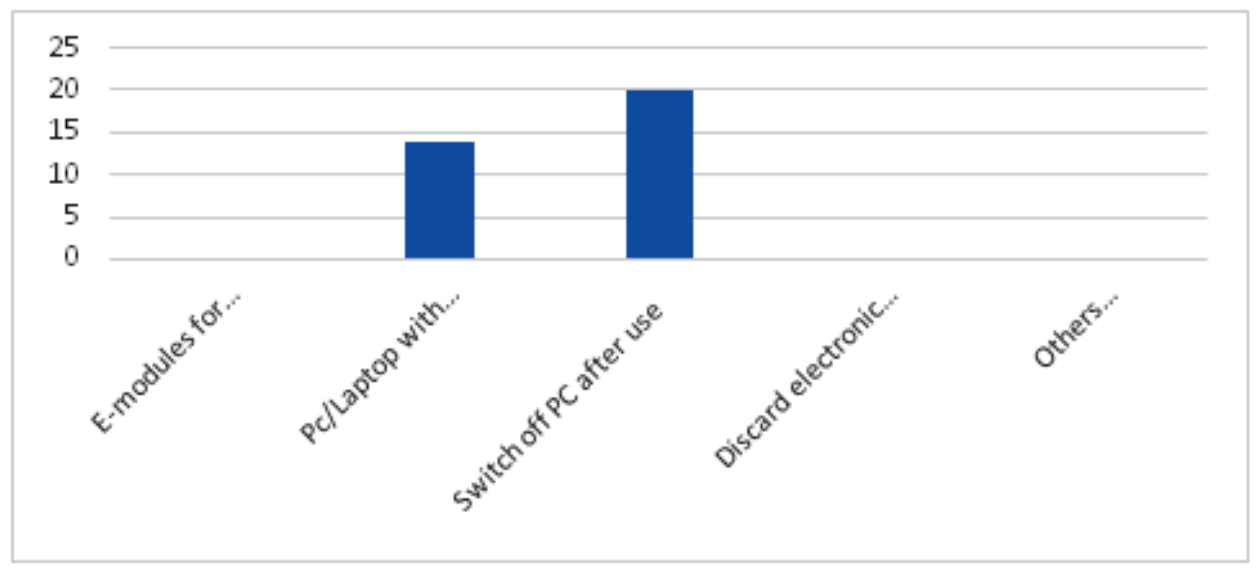

Figure 3. Items followed in promoting Green ICT 
While asking the respondents to mention what inspires most in adopting Green practices, $97 \%$ of the respondents mention it is due to the pressure imposed by the regulatory authorities, suppliers, customers, the perceived success of their competitors and lastly due to the organizational concern. Only $3 \%$ among them mention it as a social responsibility to remain the environment Green. Both individual awareness and regulatory trends create opportunities and risks for businesses.

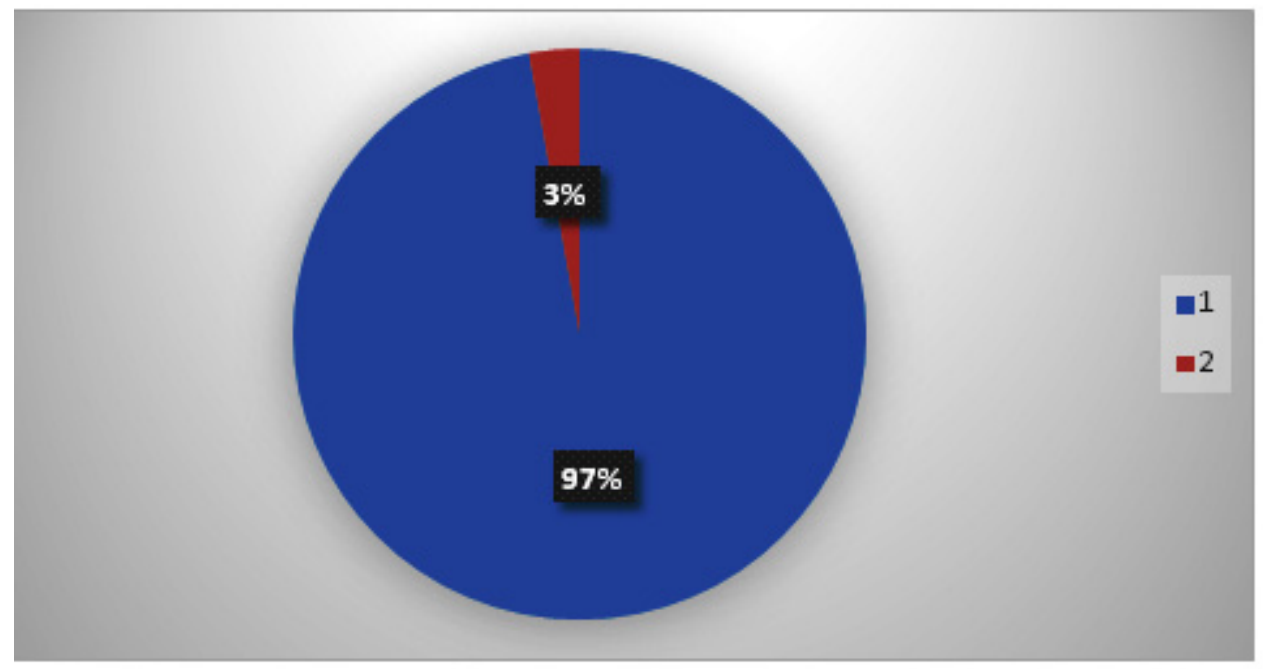

Figure 4. Institutional pressure Vs Individual Consideration

At the end of the questionnaire respondents are asked to mention the various possible impacts on their adoption of Green practices on organizational premises where $59 \%$ answered it has a positive impact on energy savings, $26 \%$ answered Climate change awareness and rest $15 \%$ refused to answer it.

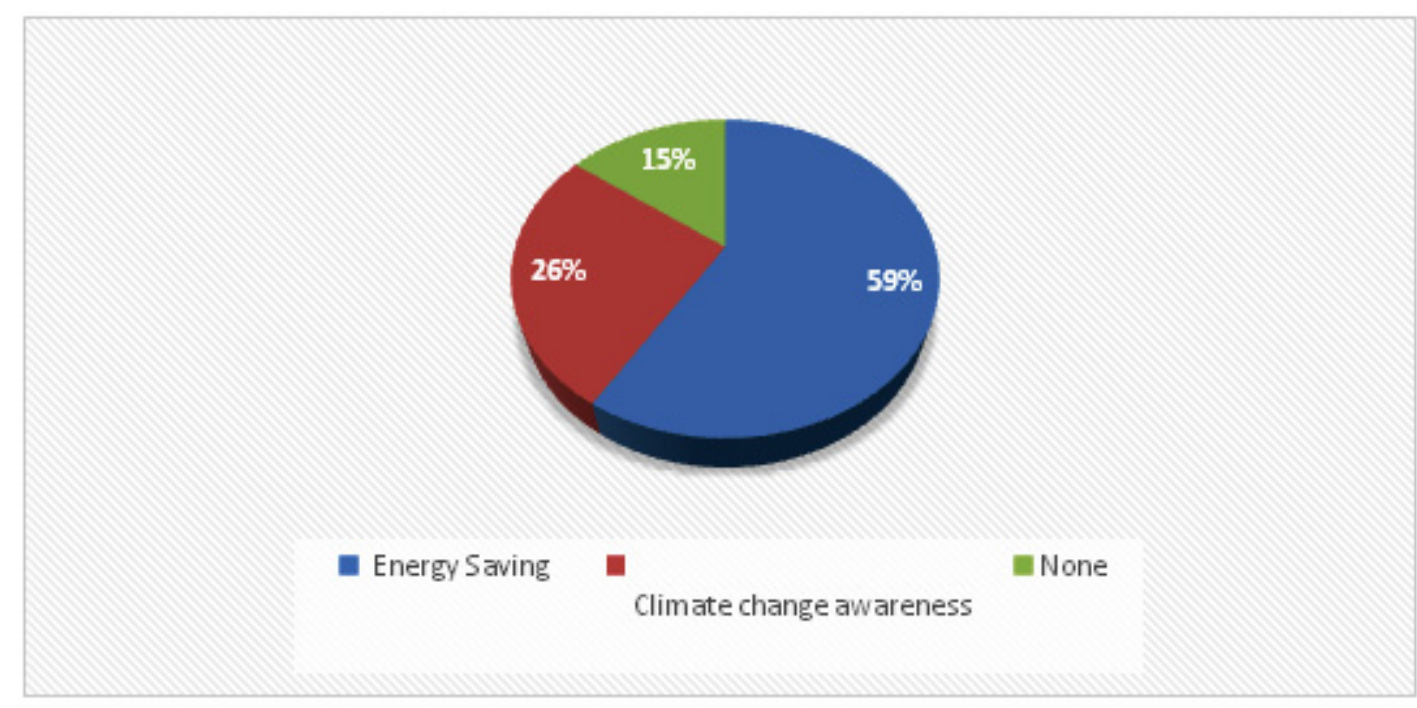

Figure 5. Impact of Green Practices

\section{Conclusion}

The level of awareness regarding Green practices is still very poor. Energy saving attitudes with few recycling initiatives are not enough satisfactory for long term sustainability of the factories. Traditional building structures are energy inefficient. So the easiest way for the existing companies would be to incorporate Smart Energy Management to measure how much they use and

\begin{tabular}{llllll}
\hline 74 & Journal of Information Organization & Volume & 8 & Number 2 & June \\
\hline
\end{tabular}


spent regularly on gas, water, power just to have an idea where the changes need to be made. Smart Infrastructure through improved engineering and construction industry may also be considered. For remote collaboration organizations may practice virtual meetings or collaborative learning to reduce the necessity of individual travel that would eventually lower costs, carbon emissions in businesses. The level of awareness on Green ICT needs to be considered as National Agenda where initiatives would be taken from both public and individuals. In order to make our environment worth living, awareness in the form of campaigns and programs, social media pages, press releases need to be increased. We should need to understand the negative consequences of not taking care of our environment that would result in lowering the quality of life leading the world $\mathrm{n}$ great danger in near years.

\section{References}

[1] Blue \& green tomorrow (2013). Available from: http://blueandgreentomorrow.com/2013/04/11/csr-and-sustainability-practicesfound-to-boost-public-perception-of-firms/ [12 ${ }^{\text {th }}$ Dec 2015]

[2] Channel News Asia, (2013). Eco-Business. Available from: http://www.eco-business.com/news/singapores-first-green-factoryembraces-environmentally-friendly-practices/ [12 ${ }^{\text {th }}$ Dec 2015].

3] Chou., C. D., Chou., Y., A. (2011) Awareness of Green IT and its value model. p.450.

[4] Din., N., Haron., S., Aahmad., H. (2013). The level of awareness on the Green ICT concept and Self-directed learning among Malaysian Facebook Users. ASEAN Conference on Environment-Behavior Studies, p. 464-473.

[5] Elliot, S. (2011). Transdisciplinary perspectives on environmental sustainability: A resource base and framework for ITenabled business transformation, Management Information Systems Quarterly. 35 (3) 197-236.

[6] Green Industry Analysis 2015- Cost \& Trends, (2015). Available from: https://www.franchisehelp.com/industry-reports/ green-industry-report/ [13 ${ }^{\text {th }}$ Dec 2015].

[7] Molla, A., Pittayachawan, S., Corbitt, B., Deng, H. (2009).An international comparison of Green IT diffusion, International Journal of e-Business Management 3 (2) 1-23.

[8] Molla., A., Cooper., V., Pittayachawan., S. (2009). The Green IT Readiness ( G-Readiness) of Organizations: An Exploratory Analysis of a Construct and Instrument. 29 (4) 67-96.

[9] Robinson., Lewis. (2015). Triple Pundit. Available from: http://www.triplepundit.com/2015/05/green-initiatives-improve-brandsperceived-value/ [15 $5^{\text {th }}$ Dec 2015].

[10] Sharp, (2015). Available from: https://www.sharp.eu/cps/rde/xchg/eu/hs.xsl/-/html/sharps-green-mind.htm\#/cps/rde/xchg/ eu/hs.xsl/-/html/77466_green-factories.htm [14th Dec 2015]. 